\title{
Políticas de inovação no Brasil: uma análise com base na PINTEC 2008
}

Ana Paula Avellar*

RESUMO - O objetivo desse artigo é apresentar as principais políticas de inovação em vigência no Brasil e discutir sobre a participação das empresas brasileiras em tais políticas. $\mathrm{O}$ artigo inicia com uma breve apresentação de alguns indicadores de inovação, e em seguida, caracteriza as políticas de inovação recentes no país. São destacados os resultados apresentados pela PINTEC 2008 no que tange à participação das empresas - quanto ao setor industrial e quanto ao porte - nos programas disponíveis de apoio à inovação no Brasil. O resultado encontrado revela um crescimento no número de programas de apoio à inovação no Brasil e na participação das empresas em tais programas, porém, ainda não acompanhado por uma substancial melhoria nos indicadores de inovação.

Palavras-chave: Políticas de inovação. Brasil. PINTEC.

\section{INTRODUÇÃO}

O objetivo desse artigo é apresentar, de maneira sintética, as principais políticas de inovação em vigência no Brasil e discutir a participação das empresas brasileiras em tais políticas, quanto ao porte e ao setor industrial. Para isso, o artigo está organizado em quatro partes, incluindo essa breve introdução. $\mathrm{Na}$ segunda parte desenvolve-se uma breve caracterização das políticas de inovação recentes no país. Na terceira parte são destacados os resultados apresentados pela PINTEC 2008 no que tange à participação das empresas - quanto ao setor industrial e quanto ao porte - nos programas disponíveis de apoio à inovação no Brasil. Na quarta e última parte encontram-se algumas considerações finais.

A política de apoio à inovação vem ganhando, nos últimos anos, papel de destaque na agenda de política econômica. Com intuito de acelerar o desenvolvimento das atividades inovativas pode-se fazer uso de diversos instrumentos de política de inovação como os incentivos fiscais e os incentivos financeiros, que por sua vez, possuem diversos formatos, sejam subsídios a projetos de pesquisa, financiamento via fundos financeiros, compras do setor público ou política de atração de Investimento Externo Direto em atividades intensivas em P\&D.

No Brasil, alguns dos principais esforços do governo nesse sentido verificam-se com a entrada em vigor da Lei de Inovação n ${ }^{\circ} 10.793$, promulgada em 2005, criada com o objetivo de fornecer incentivos à inovação e à pesquisa científica e tecnológica; com a Lei do Bem (Lei

\footnotetext{
* Doutora em economia da indústria e da tecnologia pela Universidade Federal do Rio de Janeiro. É professora do Instituto de Economia da Universidade Federal de Uberlândia e coordenadora do Núcleo de Economia Aplicada (NEA/IE/UFU). Endereço eletrônico: anaavellar@ie.ufu.br.
} 
$\mathrm{n}^{\circ}$ 11.196, de 21 de novembro de 2005) regulamentando os incentivos fiscais às atividades inovativas; e com a constituição do Plano de Ação em Ciência, Tecnologia e Inovação para o Desenvolvimento Brasileiro (2007-2010) em 2007.

Segundo dados do MCT (2010), o apoio à inovação vem crescendo acentuadamente. No âmbito da Financiadora de Estudos e Projetos (Finep/MCT) o volume de crédito aprovado que era de R \$ 574 milhões, em 2005, alcançou em 2009 R \$ 1,7 bilhão; e a subvenção econômica aportou cerca de R \$2 bilhões de 2006 a 2010.

No entanto, alguns indicadores de inovação ainda mostram uma trajetória lenta de crescimento no esforço inovador das empresas brasileiras. Entre os anos 2006 e 2008, o gasto doméstico bruto em P\&D (GERD) em relação ao PIB passou de 1,02\% para 1,09\% do PIB, representando um aumento de $6,8 \%$ no período. Porém, destaca-se que nesse período esse indicador de esforço inovador cresceu a um ritmo mais lento do que a economia, dado que o crescimento do PIB foi de $11,5 \%$ de 2006 a 2008.

Os recém divulgados resultados da PINTEC 2008 revelam que entre 2006 e 2008 houve um aumento na taxa de inovação, ou seja, no número de empresas que implementaram produto ou processo tecnologicamente novo ou substancialmente aprimorado. A taxa de inovação passou de 34,4\%, no período 2003-2005, para 38,6\%, entre 2006-2008, para o conjunto das empresas brasileiras. Ao se considerar os dois tipos de inovação (produto e processo) verifica-se que $22,9 \%$ das empresas inovaram apenas em produto e 32,1\% inovaram apenas em processo. É importante destacar que, no que se refere ao mercado, a taxa de inovação revela que mesmo sendo $22,9 \%$ das empresas industriais que tenham inovado em produto, somente $4,1 \%$ implementaram produto novo ou substancialmente aperfeiçoado para o mercado nacional.

Quanto ao porte da empresa mantém-se o padrão apresentado nas edições anteriores da PINTEC, em que o maior número de inovadoras concentra-se nas empresas industriais com 500 ou mais pessoas ocupadas: $71,9 \%$ são inovadoras em produto ou processo, enquanto as empresas com até 29 pessoas ocupadas, 36,9\% são inovadoras em produto ou processo. Outro indicador importante que se reduziu, porém, ainda mantém o padrão da PINTEC 2005, é o percentual de empresas que consideraram a aquisição de máquinas e equipamentos para inovação como relevante para desenvolver suas inovações, que em 2005 era de 80,6\% e em 2008 foi de $77,7 \%$.

Quanto à participação das empresas nas políticas de apoio à inovação pode-se destacar que houve um aumento no percentual das empresas inovadoras que participaram ao menos de um instrumento de apoio do governo no período de 2006-2008 em relação ao de 2003-2005, saindo de $18,8 \%$ para $22,3 \%$. 
A partir da apresentação de alguns indicadores recentes da inovação, na próxima seção desse artigo estão caracterizados os principais instrumentos de apoio à inovação no Brasil, para em seguida, serem detalhados os resultados apresentados na PINTEC 2008.

\section{PRINCIPAIS INTRUMENTOS RECENTES DE APOIO À INOVAÇÃO NO BRA-} SIL

Os principais instrumentos de políticas de inovação no Brasil são os incentivos fiscais e os incentivos financeiros, e dentre os incentivos financeiros encontram-se as linhas de financiamento reembolsáveis e linhas de financiamento não-reembolsáveis. Destacam-se ainda os fundos de capital de risco, o programa RHAE - pesquisador na empresa (concedido pelo $\mathrm{CNPq}$ ) e programa de capital semente (denominado Criatec).

Os incentivos financeiros às atividades inovativas, como os fundos financeiros e o financiamento direto, são muito utilizados como instrumento de política de inovação por diversos países. Avellar (2008) aponta algumas especificidades do instrumento financeiro, dentre elas o fato de serem, na sua maioria, direcionados a setores industriais, a projetos específicos ou a parcerias entre empresas e universidades. Esse tipo de instrumento dá ao governo o poder de definir claramente sua estratégia de desenvolvimento tecnológico e os impactos socioeconômicos desejados, já que às empresas, por outro lado, cabe desenvolver projetos buscando apenas o benefício privado.

Outra característica importante desse instrumento está no fato de não excluir, a priori, nenhuma empresa do programa, diferentemente dos incentivos fiscais que são fortemente dirigidos às empresas lucrativas com imposto de renda a pagar.

Os incentivos fiscais, por sua vez, diferentemente dos programas de incentivos financeiros, possibilitam que as decisões de "onde" e "como gastar" em P\&D sejam realizadas pelas empresas, compreendidas, nesse caso, como os agentes mais capacitados para avaliar qual projeto será mais bem sucedido no mercado. Ao reduzir os custos de $\mathrm{P} \& \mathrm{D}$, os incentivos fiscais também atacam as externalidades que, segundo uma visão mais conservadora, seria um dos principais argumentos favoráveis à intervenção governamental. Outra característica dos incentivos fiscais em relação aos financeiros encontra-se no fato desse instrumento ser considerado mais transparente e mais flexível, dado que pode atender a diferentes objetivos, tipos de empresas e setores industriais simultaneamente; e por não possuir um teto-limite de crédito como possuem os créditos diretos, estando diretamente relacionados com a tomada de decisão e os gastos efetivados pelas empresas. 


\subsection{INCENTIVOS FINANCEIROS}

No que se refere às políticas de incentivos financeiros reembolsáveis no BNDES e na FINEP destacam-se as seguintes linhas de financiamento: Inova Brasil e Juro Zero, da Finep; e o Programa de Desenvolvimento da Inovação, do BNDES, criado em 2006, que sofreu reformulações relevantes em 2008.

Existem significativas semelhanças na concepção das linhas de financiamento e nas suas modalidades de operação, o que faz com que tanto a Finep como o BNDES tendem a atrair os mesmos clientes potenciais. Portanto, a escolha do melhor canal será em função também da história de relacionamento da empresa com a agência, do grau de exigência de cada uma quanto ao enquadramento dos projetos, das avaliações de risco dos clientes, entre outros (ANPEI, 2009).

Dentre os programas de financiamento reembolsável, até 2008, destacava-se o Programa Pró-Inovação da Finep. No período 2005 a 2007, esse programa havia contratado em média 46 operações, o que englobava um valor aproximado de $\mathrm{R} \$ 553$ milhões anuais. Neste contexto, os principais setores beneficiados foram: petroquímico, farmacêutico, máquinas e equipamentos em geral e material de transporte. Em 2008, a Finep iniciou um processo de reformulação desse programa de financiamento, criando-se assim um novo programa, denominado Inova Brasil (Programa de Incentivo à Inovação nas Empresas Brasileiras). Como principal diferenciação introduzida no Programa, vale destacar a criação de três grandes categorias de projetos, cada uma delas com uma taxa de juros determinada. Segundo o MCT (2010), desde 2007, foram apoiados 166 projetos, um total de recurso de $\mathrm{R} \$ 2,8$ bilhões, crescendo de $\mathrm{R} \%$ 557,8 milhões em 2007 para $\mathrm{R} \$ 1,7$ bilhão em 2009.

A Finep possui outra linha de financiamento criada em 2006 e denominada Programa Juro Zero. Neste programa encargos financeiros são reduzidos e os procedimentos operacionais simplificados, com intuito de conceder auxílios principalmente para que micro e pequenas empresas tenham condições de desenvolver projetos de inovação tecnológica. Esta linha de financiamento é corrigida pelo Índice de Preços ao Consumidor Amplo (IPCA) e é dividida em até 100 parcelas, sendo que o financiamento varia de $\mathrm{R} \$ 100$ mil a $\mathrm{R} \$ 900$ mil, limitado a 30\% do faturamento da empresa no ano anterior. Em termos comparativos, o Programa Juro Zero é bem menos expressivo que o Pró-Inovação, representando menos de $2 \%$ e pouco mais de $3 \%$, respectivamente, do valor e do número de operações contratadas no âmbito Pró-Inovação. O programa Juro Zero contratou 17 operações em 2006 e 30 em 2007; e em termos de valor, essas operações foram bem menos expressivas: $\mathrm{R} \$ 9$ milhões em 2006 e R \$ 17 milhões em 2007 (ANPEI, 2009). Segundo dados do MCT (2010) desde 2007 foram apoiados 47 projetos de 
empresa, totalizando $\mathrm{R} \$ 36,7$ milhões de recursos.

O BNDES possui pouca tradição no financiamento de projetos de inovação, de modo que as linhas de financiamento, com encargos reduzidos com a finalidade de incentivar a inovação tecnológica, foram criadas recentemente. Destaca-se como uma importante linha de financiamento do BNDES denominada Inovação Tecnológica, criada em 2008, substituindo o Programa de Desenvolvimento de Inovação (PDI), instituído em 2006. Essa linha é destinada a financiar projetos de pesquisa, desenvolvimento e inovação com valor superior a $\mathrm{R} \$ 1$ milhão, que apresentem risco tecnológico e oportunidade de mercado, compreendendo o desenvolvimento de produtos e/ou processos novos (para o mercado nacional) ou significativamente aprimorados.

Um elemento positivo das linhas de financiamento do BNDES é o fato que os pedidos de concessão são feitos diretamente ao Banco, sem a necessidade de intermediação de terceiros. A taxa de juros anual é de 4,5\% e o prazo máximo para pagamento é de 14 anos, sendo que a participação do Banco pode chegar a 100\% dos itens financiáveis, definidos nas políticas operacionais.

Há outra linha de financiamento do BNDES chamada Capital Inovador, que é resultado da reformulação de um programa, criado em 2006, denominada Inovação-Produção. Esta linha tem como objetivo primordial a empresa, sendo assim, a avaliação do Banco está focada na estratégia da empresa e em seus planos de inovação. Neste caso, o valor mínimo do financiamento é de $\mathrm{R} \$ 1$ milhão e o máximo de $\mathrm{R} \$ 200$ milhões por grupo econômico a cada 12 meses.

Outro tipo de financiamento são os incentivos financeiros não-reembolsáveis. Um programa que se encaixa nessa linha é a subvenção econômica definida como a aplicação direta de recursos orçamentários nas empresas para a realização de atividades de pesquisa e desenvolvimento. A Finep, por meio de chamadas públicas, desde 2006, dá início ao Programa de Subvenção Econômica. Essas chamadas especificavam, entre outros itens, os temas e áreas a serem apoiados, o valor mínimo da subvenção, as exigências de contrapartida por parte das empresas, além dos critérios de pontuação dos projetos. No período de 2006 a 2008, houve apenas três chamadas públicas, uma em cada ano. Em 2006, a chamada pública apresentou grande demanda das empresas, atraindo 1.100 empresas que enviaram suas propostas, das quais 155 foram aprovadas. No ano seguinte o número de propostas cresceu, pois foram apresentadas 2.500 propostas, o que gerou a contratação de 174 projetos perfazendo um montante de $\mathrm{R} \$ 314,2$ milhões. Esse crescimento manteve-se em 2008, tendo sido aprovados 209 projetos que geraram um montante de $\mathrm{R} \$ 453$ milhões de financiamento. 
A Finep opera outra modalidade de recursos não-reembolsáveis, denominada Subvenção para a contratação de pesquisadores. Nesta modalidade, utiliza-se a subvenção como forma de contratação de profissionais com titulação de mestre ou doutor que por sua vez serão empregados em atividades inovativas, contribuindo para a inovação e desenvolvimento tecnológico das empresas. O benefício é obtido sob a forma de concessão de um ressarcimento semestral das despesas advindas do pagamento dos salários dos pesquisadores contratados, que por sua vez se limita a até $60 \%$ do valor dessa remuneração, nas regiões abrangidas pelas extintas Sudam e Sudene, e a até 40\%, nos demais casos. Além disto, o limite superior para a subvenção é de $\mathrm{R} \$ 7$ mil para doutores e $\mathrm{R} \$ 5$ mil para mestres, por um período de até três anos improrrogáveis.

Outro programa de financiamento com recursos não-reembolsáveis operado pela Finep é o Programa Primeira Empresa Inovadora (PRIME). Este programa foi criado em 2008 com o objetivo de dar condições financeiras favoráveis para um conjunto de empresas nascentes de alto valor agregado se consolidarem. O PRIME prevê investimento de R \$1,3 bilhão até 2012 em projetos que proporcionem a consolidação dos negócios de alto valor agregado, bem como a formação de novos agentes empreendedores.

Esse programa foi constituído por meio de convênios de cooperação institucional firmados entre a Finep e 17 incubadoras-âncoras. No projeto é previsto que cada rede de incubadoras auxilie em média 100 empresas e para a viabilidade desse programa a Finep transfere para cada uma destas redes um montante de R $\$ 12$ milhões. Além disso, o PRIME atua em benefício de qualquer empresa com menos de 24 meses de idade, desde que ela desenvolva atividade de pesquisa e desenvolvimento, além de dispor de um produto que seja viável economicamente (para que a linha de investimento obtenha retornos favoráveis, já que é não-reembolsável). Em 2009, os 17 convênios contavam com 1.381 empresas contratadas, sendo que cada uma dessas empresas recebeu, nesse ano, R \$ 120 mil pela subvenção, alcançando um total de R \$ 166 milhões (MCT, 2010).

Outro programa com recursos não-reembolsáveis, mas operado pelo BNDES, é o Fundo Tecnológico (Funtec) cujo objetivo é financiar por meio de recursos não-reembolsáveis projetos em áreas consideradas de interesse estratégico para o Brasil. Para tanto, o projeto não financia a empresa diretamente, mas indiretamente ao financiar instituições tecnológicas e instituições de apoio ao desenvolvimento tecnológico, com a participação de empresas.

Existem algumas áreas que são definidas como prioritárias no recebimento de incentivos e benefícios: energias renováveis; meio ambiente - com foco em soluções para o controle de emissões poluentes de veículos e de indústrias -; e saúde, principalmente no que condiz com 
princípios ativos e medicamentos para doenças já negligenciadas, fármacos com base em técnica do DNA recombinante e também o apoio à construção de infraestrutura de inovação em saúde. Há orientações que sugerem que 85\% dos recursos do Funtec sejam destinados a estas áreas, e o restante correspondente a $15 \%$ seja aplicado livremente de acordo com a qualidade dos projetos apresentados.

Os Fundos de Capital de Risco também são instrumentos de apoio à inovação que podem ser definidos como uma operação de crédito que tem o seu pagamento vinculado aos resultados financeiros obtidos pela empresa em consequência da execução do projeto de P\&D. Neste tipo de Fundo, o investidor se compromete em assumir parte do risco tecnológico e também comercial do projeto. Devido a notável dificuldade no processo de captação de recursos privados em prol do financiamento dos riscos que os projetos apresentam (característica de países em desenvolvimento), estão sendo constituídas por algumas agências governamentais fundos mistos, como, por exemplo, o Projeto Inovar da Finep; o projeto de Capitalização de Empresas e o Programa Criatec do BNDES e o Sebrae.

\subsection{INCENTIVOS FISCAIS}

Os incentivos fiscais são oferecidos basicamente sob dois formatos, sendo eles: dedução do imposto de renda e crédito fiscal. A dedução do imposto de renda tem sua base de incidência nos lucros das empresas inovadoras. Já o crédito fiscal atua na redução da alíquota do imposto a pagar. Um ponto favorável a esse instrumento é o fato de ele abranger "teoricamente" todos os tipos de empresa. Além disto, os incentivos fiscais reduzem os custos com equidade, independentemente do tipo de projeto de P\&D que está sendo empreendido, do tamanho da empresa, da sua origem de capital e do setor de atividade ao qual participa (AVELLAR, 2008).

No caso brasileiro é um dos instrumentos bastante utilizados para estimular a inovação e o desenvolvimento tecnológico, especialmente para estimular atividade de P\&D. Com a Lei do Bem (Lei n.11.196), instituiu-se um novo formato aos incentivos fiscais à inovação, que além de terem representado uma significativa ampliação dos benefícios concedidos às empresas pela Lei 8.661 de 1993, trouxeram como grande atrativo o fato de serem automáticos, isto é, as empresas não necessitam mais apresentar projeto prévio para após serem apreciados começarem a usufruir dos incentivos.

Alguns pontos merecem destaque sobre esse instrumento. Pode ser feita a dedução, para efeito de apuração do lucro líquido e da base de cálculo da Contribuição Social sobre o Lucro Líquido (CSLL), do valor correspondente à soma dos dispêndios realizados com pesquisa tecnológica e desenvolvimento de inovação tecnológica classificáveis como despesas operacio- 
nais pela legislação do Imposto de Renda de Pessoa Jurídica (IRPJ). Outro elemento importante refere-se à redução de 50\% do Imposto sobre Produtos Industrializados (IPI) incidente sobre equipamentos, máquinas, aparelhos e instrumentos, bem como os acessórios sobressalentes e ferramentas que acompanhem esses bens, destinados à pesquisa e ao desenvolvimento tecnológico.

Além disso, verifica-se a depreciação integral, no próprio ano da aquisição, de máquinas, equipamentos, aparelhos e instrumentos novos, destinados à utilização nas atividades de pesquisa tecnológica e desenvolvimento de inovação tecnológica, para efeito de apuração do IRPJ e da CSLL; e a amortização acelerada, mediante dedução como custo ou despesa operacional, no período de apuração em que forem efetuados, dos dispêndios relativos à aquisição de bens intangíveis, vinculados exclusivamente às atividades de pesquisa tecnológica e desenvolvimento de inovação tecnológica, para efeito de apuração do IRPJ.

Segundo dados do MCT (2010), a Lei do Bem apoiou por ano 130 empresas em 2006, 299 empresas em 2007 e 441 empresas em 2008, ou seja, um crescimento de 240\% no período. Destaca-se também que o investimento em P\&D das empresas beneficiárias pela Lei do Bem se ampliou de 2,1 bilhões em 2006, para 8,1 bilhões em 2008. Chama a atenção a forte concentração regional das empresas beneficiárias, com a região Sudeste responsável por $85 \%$ dos recursos aplicados em P\&D, característica similar à concentração regional já apresentada por outro programa de incentivo fiscal o Programa de Desenvolvimento Tecnológico Industrial (PDTI) como destaca Avellar (2008).

\section{EVIDÊNCIAS EMPÍRICAS COM BASE NA PINTEC 2008}

Os dados contidos na PINTEC 2008 no que se refere às políticas de apoio do governo às atividades inovativas contemplam incentivos fiscais, financiamento, subvenções, entre outras. Com essas informações é possível conhecer o perfil das empresas beneficiárias no que tange ao porte e ao setor de atuação, assim como a distribuição de uso dos programas de apoio entre as empresas. É importante ressaltar que a PINTEC vem demonstrando, em todas as edições, um contínuo esforço no aprimoramento do questionário, destacando-se as questões pertinentes à temática das políticas de apoio à inovação. Na PINTEC 2008 é possível, de maneira mais detalhada, compreender os diferentes instrumentos de política disponíveis no Brasil ao analisá-los separadamente, tornando possível a avaliação sobre a efetividade de cada um desses programas vigentes no país.

No conjunto das industrias inovadoras, um número mais expressivo de empresas, 8.700 empresas $(22,8 \%$ ), participou de pelo menos um benefício do governo para desenvolver 
inovações de produto e/ou processo entre 2006 e 2008. Esse percentual é maior do que o apresentado nas edições anteriores das PINTECs em que, respectivamente, 18,7\% (em 2003) e 19,2\% (em 2005) das empresas inovadoras afirmaram receber algum suporte do governo à inovação.

Dentre os diversos instrumentos de apoio à inovação disponíveis destaca-se, como o mais utilizado, o financiamento para compra de máquinas e equipamentos pelas empresas inovadoras (14,2\%), mantendo o padrão encontrado na PINTEC 2005. Observa-se também que os menos utilizados foram o instrumento de subvenção econômica $(0,5 \%)$ e o financiamento a projetos de P\&D e inovação tecnológica em parceria com universidades ou institutos de pesquisa $(0,8 \%)$.

No que tange ao recorte de porte ou tamanho da empresa na participação em programas de apoio à inovação verifica-se que do total de inovadoras, 22,2\% possuem entre dez e 99 pessoas, 23,7\% possuem entre 100 e 499 pessoas ocupadas e 36,8\% possuem 500 ou mais pessoas ocupadas. De acordo com a PINTEC 2005 essa distribuição era: 17,3\% das empresas que empregam entre 10 e 99 pessoas, 24\% das que empregam entre 100 e 499 pessoas ocupadas e $40,9 \%$ possuem 500 ou mais pessoas ocupadas. Conclui-se que, em relação ao período 2003-2005, o período 2006-2008 apresentou um aumento na participação das empresas de pequeno porte e uma redução das empresas de grande porte nos programas públicos de apoio à inovação.

Observa-se também que a participação dessas empresas de menor porte está concentrada em programas de incentivos financeiros, como financiamento a projetos de P\&D e inovação tecnológica com e sem parcerias com universidades, representando, respectivamente, 68\% (360 empresas) e 47\% (151 empresas) das empresas beneficiárias desses programas.

Quanto aos programas de incentivos fiscais regulamentados pelas leis de P\&D e inovação tecnológica (Lei no 8.661, de 2 de junho de 1993; e cap. III da Lei no 11.196, de 21 de novembro de 2005) e pela Lei do Bem (Lei no 11.196, de 21 de novembro de 2005) a participação foi de $1,1 \%$ das empresas industriais inovadoras. Destaca-se, no entanto, que esse percentual sobe para $16,2 \%$ das empresas inovadoras, quando é feito o recorte por porte e consideram-se somente empresas com 500 ou mais pessoas ocupadas. As empresas de maior porte somente são mais beneficiárias dos programas de apoio à inovação no caso dos incentivos fiscais à P\&D, representando 44\% das empresas que receberam esse benefício (193 empresas). Dentre os setores beneficiários pelos incentivos fiscais à $\mathrm{P} \& \mathrm{D}$ o setor que teve maior participação foi o de artigos de borracha e plástico representando $23 \%$ do total de empresas que participaram desse programa. Quanto aos incentivos fiscais referentes à lei de informática, o setor de equipamen- 
tos de informática teve maior representatividade (20\%) entre as empresas beneficiárias.

Quanto aos programas de subvenção econômica, 207 empresas industriais foram beneficiadas, dentre as quais 39 empresas (19\%) concentram-se no setor de artigos de vestuário e confecção.

No que tange ao programa de financiamento sem parcerias com universidades, das 526 empresas, $112(22 \%)$ das empresas encontram-se no setor de produtos químicos. Nos programas de financiamento com parcerias com universidades, por sua vez, das 323 empresas beneficiárias, 54 das empresas atuam no setor de fabricação de madeira, representando $17 \%$ das empresas beneficiárias.

No que se refere aos programas de apoio à compra de máquinas e equipamentos, destaca-se que ao se considerar o conjunto das 8.653 empresas inovadoras que receberam apoio do governo, 63\% participaram de programa para compra de máquinas e equipamentos representando 5.436 empresas. O setor que apresenta a maior participação, com 796 beneficiadas é o setor de produtos alimentícios.

\section{CONSIDERAÇÕES FINAIS}

Desde 2003 muitos esforços da política de inovação no Brasil vêm sendo feitos no sentido de ampliar os incentivos fiscais e financeiros, criar programas de subvenção direta às empresas, criar linhas de financiamento com juros reduzidos e subvencionar a contratação de pesquisadores. A criação de um grande número de instrumentos públicos de apoio à inovação somada a uma melhor perspectiva dos empresários quanto à importância da inovação como elemento determinante da competitividade, tem contribuído ativamente para o aumento da participação das empresas nos programas de apoio à inovação.

Observa-se a partir da PINTEC 2008 um aumento no número das empresas beneficiárias, e uma pequena, mas importante, alteração no que se refere à concentração das beneficiárias em empresas de grande porte. Vê-se, em relação ao período 2003-2005, que no período 2006-2008 ampliou-se o número de empresas de pequeno porte nos programas de apoio à inovação, estimuladas em grande medida pelos programas de financiamento a projetos de $\mathrm{P} \& \mathrm{D}$ com e sem parceria com universidades.

Outra constatação importante apresentada pela PINTEC 2008 refere-se ao fato de que programas analisados atuam em diferentes setores industriais, distribuindo de alguma maneira os recursos de apoio à inovação. Nota-se, porém, que muitos setores industriais possuem participações muito pouco representativas o que leva ao questionamento sobre a abrangência de tais programas de apoio à inovação. 
Porém, mesmo diante desse crescente esforço na elaboração de novos instrumentos de políticas de apoio à inovação no Brasil e do aumento de empresas beneficiárias, não é possível ainda observar, em termos agregados, substanciais modificações virtuosas no comportamento das empresas industriais brasileiras.

Nesse momento, diante desse novo conjunto de informações sobre o comportamento inovador das empresas brasileiras a partir da PINTEC 2008 faz-se necessário o desenvolvimento de novos estudos com intuito de compreender a abrangência e mensurar os efeitos de tais políticas de inovação não apenas em termos agregados, mas também no desempenho dessas empresas beneficiárias, para assim, orientar os formuladores de política em busca da eliminação dos problemas do desenvolvimento da inovação no Brasil.

\section{REFERÊNCIAS}

ANPEI. Os novos instrumentos de apoio à inovação: uma avaliação inicial. Brasília, DF: Centro de Gestão e Estudos Estratégicos. Associação Nacional de Pesquisa e Desenvolvimento, 2009.

AVELLAR, A. P. M. Avaliação de políticas de apoio à inovação no Brasil: impacto dos incentivos fiscais e incentivos financeiros: Menção Honrosa. São Paulo: Prêmio CNI de Economia, Categoria Economia Industrial , 2008.

AVELLAR, A. P. M. Impacto das políticas de fomento à inovação no Brasil sobre o gasto em atividades inovativas e em atividades de P\&D das empresas. Estudos Econômicos, v. 39, p. 629-649, 2009.

CRUZ, C.H.B.; CHAIMOVICH, H. Relatório UNESCO sobre Ciência 2010. Capítulo 05: Brasil. UNESCO, 2010.

IBGE. Pesquisa Industrial de Inovação Tecnológica 2008. Rio de Janeiro, 2010.

IEDI. Desafios da Inovação - incentivos para inovação: O que falta ao Brasil. International Education Development Initiative. Fevereiro 2010. Disponível em: <www.iedi.org.br/admin_ ori/pdf/20100211_inovacao.pdf>.

RODRIGUEZ, A. et al. Conhecimento e inovação para a competitividade. Brasília: Banco Mundial e CNI , 2008.

MINISTÉRIO DA CIÊNCIA E TECNOLOGIA. Principais Resultados e Avanços do Plano de Ação em Ciência, Tecnologia e Inovação para o Desenvolvimento Nacional. Período 20072009. Brasilia, Maio de 2010. 
